\section{Apresentação da Edição Especial VII Seminário Internacional de Estudos Fronteiriços \\ - Corumbá - Brasil}

\author{
Adriana Dorfman* \\ Julian Mokwa Félix** \\ *Universidade Federal do Rio Grande do Sul, Brasil - adriana.dorfman@ufrgs.br \\ **Universidade Federal do Rio Grande do Sul, Brasil - julianmfx@gmail.com
}

Entre 07 e 09 de outubro de 2019, em Corumbá, na fronteira entre Brasil, Bolívia e Paraguai, aconteceu o VII Seminário Internacional de Estudos Fronteiriços (VII SEF). A organização do evento bianual foi feita de forma compartilhada por um grupo internacional: o Mestrado em Estudos Fronteiriços da Universidade Federal de Mato Grosso do Sul (MEF/CPAN/UFMS); o Grupo Retis da Universidade do Rio de Janeiro (UFRJ); o Portal Unbral Fronteiras da Universidade Federal do Rio Grande do Sul (UFRGS); a Universidade Federal da Grande Dourados (UFGD) e a Universidade Federal do Amapá (UNIFAP), todas do Brasil. Do Chile, participou a Universidad Arturo Pratt, através do Instituto de Estudios Internacionales (INTE/UAP), e do México, o Colegio de la Frontera Norte (El Colef). A Associação de Estudos Fronteiriços (ABS) apoiou o evento pela terceira vez.

Foram apresentados 121 trabalhos de investigadores de oito países. 0 programa contou com mesas dedicadas a temas como metodologias para os Estudos Fronteiriços e suas relações escalares; fronteiras comparadas na América Latina; gestão pública em fronteiras, mobilidade e migração. Outras atividades tais como oficinas, lançamento de livros, sessões de documentários, e uma excursão fluvial pelo rio Paraguai enriqueceram a programação. Também foram visitadas Puerto Quijarro e Puerto Suárez, cidades na fronteira boliviana, com seu mercado, faculdades de medicina e outros pontos turísticos. Na reunião de pesquisadores, discutiu-se a perspectiva de organizar a Associação Latinoamericanista de Estudos Fronteiriços.

Face ao corte dos recursos para pesquisas científicas nos distintos países da região, e, também, considerando as urgentes questões enfrentadas pelas sociedades fronteiriças, os especialistas redigiram a carta do SEF, com o seguinte conteúdo: 


\section{CARTA ABERTA DO VII SEMINÁRIO INTERNACIONAL DE ESTUDOS FRONTEIRIÇOS}

Os pesquisadores de Estudos Fronteiriços latino-americanistas, reunidos nos dias 07, 08 e 09 de outubro de 2019, em Corumbá, na Universidade Federal de Mato Grosso do Sul - Campus Pantanal, no VII Seminário Internacional de Estudos Fronteiriços, manifestam-se no sentido de serem partícipes nos processos e ações relacionados com os temas de mobilidade, migração, intercâmbio cultural, liberdade de expressão e circulação.

Considerando suas pesquisas e expertise no que se refere aos fenômenos das fronteiras nacionais e culturais, solicitam aos gestores de diferentes escalas que tomem em conta suas contribuições como base para a criação de políticas públicas que tenham como foco as regiões fronteiriças e seus distintos atores.

As fronteiras e os fronteiriços são agentes conhecedores de sua realidade e das dinâmicas cotidianas de integração latino-americana e têm condições para colaborar com o desenvolvimento do continente. E nós, como investigadores de instituições acadêmicas, queremos apoiar este processo.

Corumbá, 09 de outubro de 2019

Ao encerrar-se o evento, foi acordada a publicação de dois dossiers: este que apresentamos e outro na revista Geopantanal (ISSN 1517-4999), valorizando os melhores trabalhos apresentados no VII SEF. Em sua multiplicidade, os trabalhos procuram abordar o espaço fronteiriço a partir de diversas óticas e bases metodológicas.

Os primeiros quatro artigos trazem leituras do meio ambiente numa perspectiva sociedade-natureza. Os temas da agricultura agroecológica, seu processo de transição e a percepção dos agentes que interagem em feiras são destacados, através de metodologias de pesquisa participante, técnicas de observação e pesquisas com dados primários. Além disso, estes dados primários também são utilizados de forma a analisar as percepções ambientais da comunidade acadêmica. Este grupo inclui ainda uma análise da efetividade da gestão ambiental de empresas brasileiras atuando na hidrovia do ParaguaiParaná.

A seguir, busca-se retratar de maneira prática e teórica a interação do migrante com a fronteira e com as fronteiras entre os Estados. Os dois primeiros artigos são estudos de casos envolvendo a cidade de Corumbá-MS a partir de levantamento de dados e pesquisa de campo, em que os autores buscam entender tanto como os migrantes se relacionam com os aspectos sociais, educacionais e burocráticos quanto o movimento migratório em direção a essa cidade. Finalmente, temos um estudo de caso sobre o Brasil e os refugiados venezuelanos, a partir de um ponto de vista teórico-dedutivo.

ParaOnde!?, Porto Alegre, v.13, n.2. http://seer.ufrgs.br/paraonde Edição Especial - VII Seminário Internacional de Estudos Franteiriços 
Em uma abordagem que mescla as áreas do Direito e da Segurança, os próximos textos têm um enfoque teórico. O primeiro artigo busca, também, explorar o caso venezuelano, analisando as convergências teóricas e práticas do direito internacional aplicadas à situação do migrante e do refugiado. Transitando para uma abordagem securitária da fronteira, esta seção finaliza com uma análise das políticas de segurança e defesa na área fronteiriça do arco central.

A relação dos indivíduos e das comunidades com o território fronteiriço é o tema dos três subsequentes artigos. O primeiro, baseado em um estudo de campo no município de Mundo Novo, aborda os problemas do cotidiano fronteiriço, no qual o capitalismo estrutura e dá forma aos conflitos. Outro estudo de campo constitui o próximo artigo, em que as particularidades e singularidades de uma "faixa livre" na fronteira são analisadas e mostram suas múltiplas possibilidades e saberes. Findam esta seção dois artigos que buscam, a partir de pesquisa de campo e de entrevistas conduzidas, entender as interações e dinâmicas de diferentes feiras em área de fronteira, evidenciando o grande impacto da presença da fronteira nas dinâmicas atuantes.

Os últimos artigos desta edição especial relacionam os conceitos de território, territorialidade, fronteira, literatura e identidade. O primeiro texto propõe uma reflexão sobre a literatura e as culturas no espaço fronteiriço Brasil-Bolívia, seus impactos na formação dos indivíduos e das identidades operantes. Por fim, o espaço literário e cultural da fronteira oeste do Mato Grosso do Sul é alvo de discussão, propondo-se a abordagem dos conceitos de transculturalidade e transnacionalidade para entender as narrativas e perspectivas que permeiam esse espaço.

Os editores desta edição especial agradecem aos coordenadores gerais do VII SEF, profs. drs. Edgar Costa (MEF/UFMS) e Rebeca Steiman (Grupo Retis/UFRJ) e aos integrantes do comitê científico do evento. Seu trabalho está aqui consolidado. Agradecem ainda à equipe editorial da Revista Para Onde?!, em especial à profa. dra. Michele Lindner e ao licenciando Daniel de Souza Menezes, que agilmente oportunizaram a publicação do dossier VII Seminário Internacional de Estudos Fronteiriços.

Porto Alegre 08 de abril de 2020, em tempos de covid-19.

ParaOnde!?, Porto Alegre, v.13, n.2. http://seer.ufrgs.br/paraonde

Edição Especial - VII Seminário Internacional de Estudos Franteiriços 